
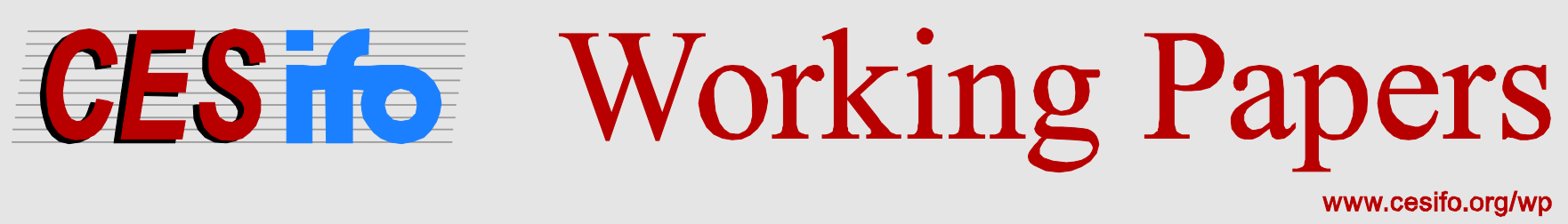

\title{
Not so Myopic Consumers Evidence on Capitalization of Energy Technologies in a Housing Market
}

\author{
Oskari Harjunen \\ Matti Liski
}

\author{
CESIFO WORKING PAPER NO. 4989 \\ CATEGORY 10: ENERGY AND CLIMATE ECONOMICS \\ SEPTEMBER 2014
}
An electronic version of the paper may be downloaded
- from the SSRN website:
- from the RePEc website:
www.SSRN.com
www.RePEc.org
- from the CESifo website:
www.CESifo-group.org/wp

\section{CESifo}




\title{
Not so Myopic Consumers Evidence on Capitalization of Energy Technologies in a Housing Market
}

\begin{abstract}
Policies affecting the cost of energy use provide correct incentives for technology choices only if there is a market reward for energy efficiency. We provide clean evidence for market efficiency by considering how heating technologies capitalize into house values using detailed Finnish register data on technologies in houses, transaction prices and socio-economic variables. We exploit variation in technologies that houses are locked into at construction time to identify the stand-alone value of having a cost-saving technology in the house. For the two main technologies, electric and district heating, the estimated price discount is $5-6 \%$ of the house value for electric heating, coming very close to the capitalized value of the cost differential obtained from external data on energy contract prices. Technologies act as "labels" with clear market valuation - the results support the idea that transparent energy-efficiency classification of houses capitalize into house prices.
\end{abstract}

JEL-Code: D120, H230, Q420, Q500.

Keywords: energy efficiency, energy paradox, discounting.

Oskari Harjunen

Economics Department

Aalto University

Helsinki / Finland

oskari.harjunen@aalto.fi
Matti Liski

Economics Department

Aalto University

Helsinki / Finland

matti.liski@aalto.fi

September 9, 2014

We have received helpful comments in seminars at EPRG Cambridge, CESifo Munich, IFN Stockholm, University of Tilburg, and VATT Helsinki. We thank Manuel Bagues, Tuukka Saarimaa, Anna Sahari, and Natalia Zinovyeva for useful comments and discussions. In particular, we are indebted to Hunt Allcott for many thoughtful comments. 


\section{Introduction}

The total consumer cost of an energy-technology consists of the price paid at purchase and costs borne later when using the technology. The sensitivity of consumers to the expected total costs of using energy technologies is of first-order importance for energy and climate policies designed to steer the technology choices through energy prices. If consumers, for one reason or another, fail to internalize total costs, producers are not rewarded for energy efficiency and more paternalistic policy interventions may be justified; for example, "consumer tools" such as mandated labeling of goods help consumers to make informed choices, or "producer tools" including energy efficiency standards and subsidies for producers can provide incentives that are missing in the market.

Energy-efficiency choices made in the building and real estate sectors are particularly important for sustainability as buildings account for more than one-third of global energy consumption and about one-fifth of energy-related greenhouse gas emissions (IPCC, 2014). The potential inefficiencies in the housing sector have been long acknowledged (e.g., Jaffe and Stavins, 1994) - various green labeling programs such as BREEAM in the UK and the US Green Building Council's LEED, and also the ones introduced through the EU Energy Performance of Buildings Directive (EPBD) have been designed to deal with market failures that may dampen the returns to energy conservation investments. Moreover, there is an emerging literature providing evidence that energy efficiency certificates influence pricing in the building and real estate sectors in a way that is suggestive of inefficiencies in pricing prior to the certification (Eichholtz, Kok, and Quigley, 2010; Kok, McGraw, and Quigley, 2011; Kahn and Kok, 2013; Eichholtz, Kok, and Quigley, 2013; Kahn, Kok, Quigley, 2014).

However, as the previous studies have not focused on the sources of the premium with which labeled buildings are shown to trade, it remains open to what extent prices in the housing market reflect the actual life-time cost of the energy technologies - the premium may arise due to willingness to pay for "greenness", or partly due to unobservable selection of buildings to labeling schemes in the commercial real estate sector ${ }^{1}$ In this paper, we consider private property and an empirical setting where the basic energy technologies

\footnotetext{
${ }^{1}$ Majority of the recent empirical literature focuses on the commercial building sector; Kahn and Kok (2013) is among the few studies that address the financial performance of green labels for private homes. Papineau (2013) analyzes the bias in the green-building premium due to nonrandom selection to labeling programs in the commercial sector. Moreover, Eichholtz el al. (2010) find that the demand for green office space varies significantly across industries suggesting that direct non-financial benefits from greenness, that differ by industry, are determining part of the green prerium.
} 
in houses are observed with ease, electric vs. district heating, so that each house has a "technology label" that requires no outside verification. We assess the value of this label quantitatively by using data from electricity and heating contracts, leading to a relatively predictable capitalized value-difference in the cost of using the two technologies.

Given that in our setting the technologies relevant for costs are well-observed in individual houses, the main empirical question is whether the market pricing of houses reflects the lower cost of district heating. Do district heating houses trade at a premium that we can reconcile with the usage cost difference obtained from the contract data? Since the cost savings accrue over long period of time, the question is if home-buyers can correctly foresee the gains from having a technology that saves financial resources in the future. In our setting, due to institutional reasons, we are able to exploit variation in heating technologies that deliver a simple service not interfering with the array of general features attributable to the house. This variation provides a strong case for identifying the stand-alone value of having an energy-saving technology in the house. By exploiting Finnish register data on transactions, socio-economic variables, technologies, and houses, we can precisely control for the house-level characteristics as well as those describing the close neighborhood of the house.

For the two main technologies considered, we find clear evidence that district heating houses trade at a premium corresponding to 5-6 per cent of the average house value, that is, about 20000 euros. This premium comes very close to the capitalized value-difference in the cost of using the two technologies, with annual discount rates close to recent-years mortgage rates. Thus, in this market, consumers are not at all myopic.

Our results are in contrast with a long sequence of papers supporting the conclusion that consumers tend to behave as if they undervalue future energy cost savings - in seminal papers by Hausman (1979) and Dubin and Mc Fadden (1984) the implied discount rates are in the range 25-30\% (see Jaffe and Stavins 1994; Allcott and Wozny 2013; but see also Busse, Knittel, and Zettelmeier, 2012).

"Energy Paradox" literature faces well-known empirical challenges — see Allcott and Greenstone (2012) — that are mostly avoided in our empirical setting. The first challenge is that energy efficiency typically confounds with other attributes of the final service from the durable good; for example, engine size of a car cannot be easily separated from energy efficiency as a feature. In our case, the final energy service is merely "heat"; the consumer cannot tell apart the technology that delivered the room temperature if not informed $:^{2}$

\footnotetext{
${ }^{2}$ Clearly, in this case as well, we cannot fully rule out unobservable technology attributes that influence the consumer's willingness to pay. However, based on an extensive survey sent to homebuilders, we do
} 
The second main problem is that energy savings from a given technology are difficult to predict; even experts can have difficulties in evaluating the capitalized savings from a given choice. Continuing with the car market illustration, it has become common to assume that future fuel costs follow a random walk so that consumers take the current price as the best prediction for the future prices as well (Anderson, Kellogg, and Sallee, 2013). In our case, the difference in costs is predictable as the pricing of electricity and district heating contracts are tightly linked due to the same set of input prices for primary energy that determine the costs of providing each type of contract.

Our data set is small but of high quality — we tend to conclude that the result found here is robust. In particular, we perform robustness analysis building on Oster (2014) to quantitatively assess the bounds for the estimated impact under pessimistic assumptions regarding the role of unobservable factors that should be accounted for. Even if our choice of house-price determinants, other than the heating technology, was no better than random and when, hypothetically, all variation in house prices could be explained $\left(R^{2}=1\right)$, the impact of district heating on the price would still be close to 4 \%. Stated differently, if our treatment (electric vs. district heating) is biased and the district heating houses have on average better unobservable attributes, the bias can at most eliminate two percentage points of the price premium.

Does the result tell more about the Finnish housing market than about market valuation of energy efficiency in general? We see twofold general lessons to be learned. First, markets seem to work with "adequate telescopic facility", also on energy issues, when choices are serious enough: life-time heating costs for an electric heating system in the Nordic context come close to the average annual family income (Sahari, 2013). The problem of inattention, that may be an important determinant of behavioral biases in other contexts (Allcott and Mullainathan, 2010), should perhaps be related to issues that arguably deserve less attention in the consumers choice set. Such biases may hamper the diffusion of technologies in important cases, including the technologies on lightning, for example. Second, our results confirm that controlling for heterogeneities is important (Bento et al., 2012). Once controlled, our study provides support for the conclusion that the market is surprisingly efficient in aggregating information; consumers produce this information by evaluating houses on a case-by-case basis, rather than relying on a public source, as we will argue.

Our research differs from the literature on green labels; however, the results are not find clear support that home-builders systematically view the technologies different in their key properties. 
consistent with the general tone of the findings in this literature. While the overall energy efficiency of buildings in our data is not a major issue and thus not our focus we have a relatively uniform fleet of houses built under a strict energy efficiency code regulating the energy efficiency of house structures - heating system in the house can be interpreted as a "label". That is, the institutional setting in our empirical case creates visibility and clarity regarding the technological properties of the houses in the market that is closely resembling the regulatory objective of the labeling systems. Moreover, since the label (electric vs. district heat) has a clean economic meaning in terms of cost savings, the degree of capitalization of this label to the house value can be relatively objectively assessed.

While in our case the labeling of technologies in the houses would be superfluous, the results support the idea that clear energy-efficiency classification of houses capitalize into house prices whenever the energy-efficiency properties of the houses cannot be easily obtained by market participants. To be sure, the result implies that consumers need no help in evaluating the life-time value of the label, only informational clarity is needed.

\section{Institutional context and data}

We consider the impact of heating technologies on the prices of single-family houses in Finland; the detailed data comes from the Helsinki metropolitan region covering also the cities of Espoo and Vantaa. Our empirical strategy builds on the following elements: (i) houses are locked-in to the technologies of interest at the time of construction; (ii) observationally similar houses co-exists in same neighborhoods in both technologies; (iii) the financial value of having one of the technologies can be assessed. The lock-in, item (i), is a pre-condition for the long-term differences in usage costs to capitalize into the house price; if the technology can be changed with ease, it is less clear why the current state of the technology should matter for the house price. In the next Section, we explain the technologies and the lock-in effect.

The selection of houses into the technologies, item (ii), should be random for the treatment effect to be unbiased. In Section 2.3, we introduce the historical reasons, including the institutional changes, that created the variation across technologies. In Section 2.2, we look at the costs of using the technologies. 


\subsection{Technologies: electric and district heating}

In the Nordic context, houses make use of a versatile set of heating technologies based on electricity, oil, gas, wood, heat pumps, and also on municipal distribution of heat. 3 The data used in this study includes information about all technologies house-by-house at the time of building, but we focus on the two main technologies in the data, that is, electric and district heating. The comparison of these technologies comes closest to the idea that for the technology to capitalize into the house price it should not be possible to change the technology with ease.

The reason for the technology lock-in is that electric heating does not require a heatwater circulation system in the structures of the house but district heating cannot operate without the system - in district heating, there is a network of radiators in which water circulates while in electric heating the radiators are heated with electricity. The watercirculation system is a structural heating technology choice in the Nordic context: if not installed during the construction, it is prohibitively costly to retrofit the house for this option later 4 Thus, houses with electric heating and without a water circulation cannot connect to a district heating system without restructuring the house. District heating is a technology that connects the house to a city-level heat distribution network, discussed in detail below, with heat generated by a combined heat and power plant $:^{5}$

A house without the water circulation in the structures can have multiple other heating technologies, including fireplaces and heat pumps; however, by definition, the technology bundle in the house excludes district heating that requires the water circulation system. In our empirical setting, we focus on houses with electric heating as their main technology if district heating is ruled out by the construction of the house. The houses are thus technologically locked in, and arguably face different future energy costs: one cannot easily move from electric heating to district heating, and, once connected to

\footnotetext{
${ }^{3}$ Electric heating has been a dominant technology in new houses, peaking at nearly $70 \%$ in year 2001 . The current share is close to $30 \%$; geothermal heat pumps are the most rapidly expanding technology (see Pippuri (2012) for an overview).

${ }^{4}$ Such a retrofit may seem easy to observers from milder climatic conditions with lighter house structures. Rather than entering the technological feasibility discussions, we look at data: in addition to the data used in the empirical analysis where the state of the technology is the construction time technology, we requested data from Helsingin Energia (HELEN) on technology switching to see if houses without the water circulation system have invested in such a system later on. We did not find a single case in the data covering Helsinki region. This robustness analysis is available on request.

${ }^{5}$ An excellent source of information about district heating basics is Finnish Energy Industries, http: //energia.fi/en/home-and-heating/district-heating
} 
district heating, the current option dominates other heat-water circulation compatible options $\sqrt[6]{6}$ An important reason for focusing on this comparison is the transparency of the cost differential in energy costs that we discuss next.

\subsection{Cost of using the technologies}

Fig. 1 shows the annual cost of heating, purely from energy use and thus excluding the sunk initial costs, for a single-family house of average size in Finland (170 m2), with average annual need for energy $(130 \mathrm{kWh} / \mathrm{m} 2) \mathrm{f}^{7}$ Coming shortly to the calculation of costs, note first that the representative house using district heat incurs an annual cost that is about 60 per cent of the corresponding energy cost of the same house heated with electricity. We are interested in this cost component of using the technology, not in the investment cost; we compare the prices of houses with pre-determined technologies. In view of Fig. 1, the difference in the monetary cost of using the two technologies remains surprisingly stable over the years depicted. In the quantitative analysis below, our data comes from the three cities in the Helsinki region; a similar pattern for the cost differential holds in Helsinki (see Fig 8 in the Appendix).

Assuming that the annual difference remains stable also in the future, as is expected to be the case due to a linkage between the electricity and district heat prices that is discussed below, we obtain the present-value energy cost difference for the two technologies. Ideally, this present value should be the price differential between the two types of houses, if they have otherwise similar characteristics. Using the average cost saving from being connected to the district-heating network in the Helsinki region, Table 1 reports the present-value savings over a 25-year time horizon for annual discount rates ranging from $1 \%$ to $5 \%$. If the cost-saving capitalizes as in this calculation, a house connected to the district-heat network should trade at a premium of about 20000 euros, provided the discount rate is close to the mortgage rates from the recent past (2-3\%). This ballpark value is close to $5 \%$ of the average house value in our data, a number useful to keep in mind for later interpretations of the estimates.$^{8}$

\footnotetext{
${ }^{6}$ We have also compared electrically heated houses to all other technologies having the heat-water circulation. The results are consistent with the expected cost difference between the technologies but the interpretation is not that sharp as in our main comparison: this analysis quantifies, in addition to the cost difference, the value of having the option to connect later on to the district heat network. Thus, the assumption of technology lock-in is not satisfied.

${ }^{7}$ See Fig 7 in Appendix for an estimate of the total costs of the main heating systems in 2010.

${ }^{8}$ Obviously, with low discount rates, the lifetime used in the calculation is the main determinant of the cost saving. We have used a time horizon common in the documents of the Building Information
} 


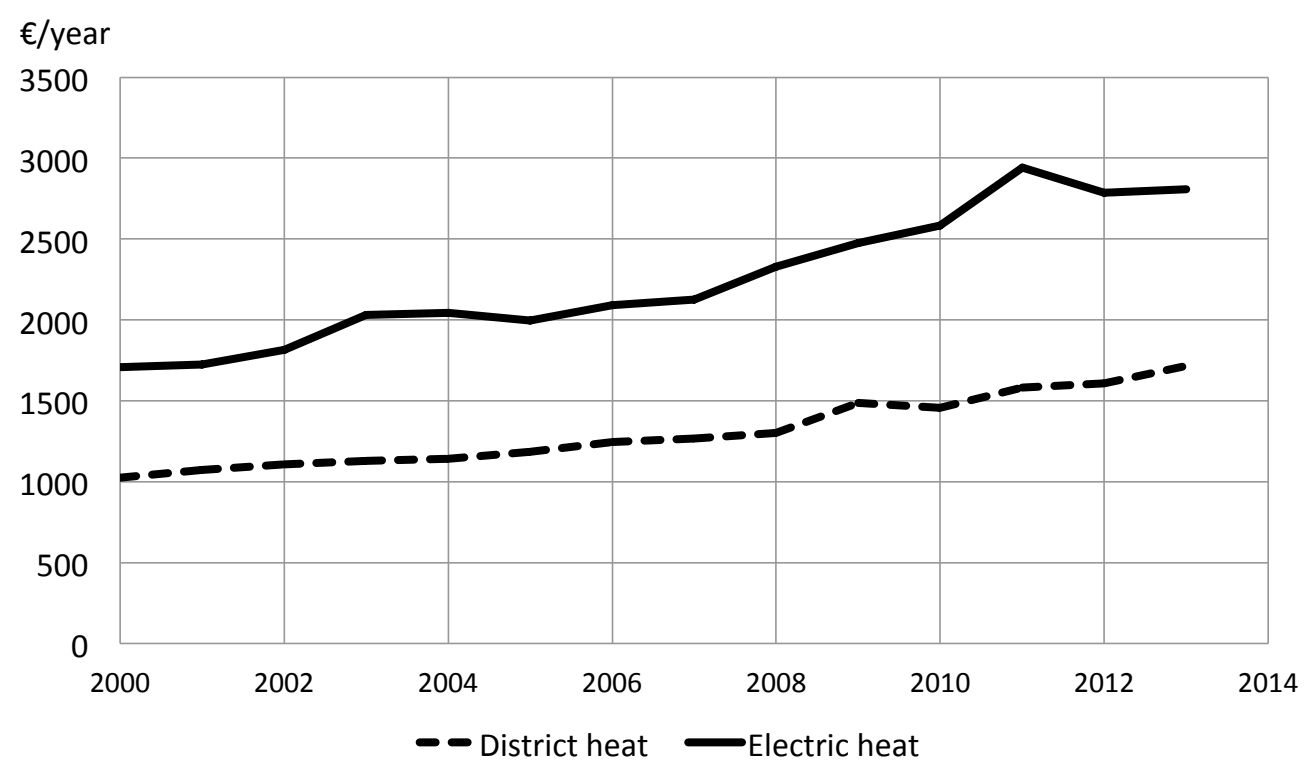

National averages in energy costs for electricity and district heating. Annual cost in 2013 euros for the reported years; house size $170 \mathrm{~m}^{2}$ with energy need $130 \mathrm{kWh} / \mathrm{m}^{2}$ (22100 kWh per year). Source: The Finnish Energy Industries.

Figure 1:

Is there a clear public perception regarding the energy cost difference outlined here? We tend to conclude that this is not the case. Conceptually, for the housing market to aggregate the information on energy costs through the house prices, it is only needed that consumers understand the costs on a house-by-house basis. Based on our estimation results, we find support for the conclusion that the market aggregates information that is otherwise difficult to obtain; we could not obtain an expert evaluation of the capitalized value of the savings in a public domain.

For the comparison presented in Table 1, we used data from electricity contracts for single-family houses (so called L1 contracts), and from the publicly reported district heat prices in the Helsinki region. The electricity retail market is deregulated; from year 2006 onwards, households have had the option to choose multiple contract types, varying from fixed-price and -term contracts to spot price contracts, creating significant variation in electricity prices per $\mathrm{kWh}$ in the country. However, there is a dominant contract type that

Foundation RTS. Both technologies are mature and relatively reliable to use. RTS runs a survey to collect information, among other issues, on home builders preferences regarding technologies: for electric heating $69 \%$ of those who chose this technology found "easy maintenance" as the prime reason for the choice; for district heating $55 \%$, had the same main reason. Source: our summary over several RTS survey waves (ca. 15000 repondents). 


\begin{tabular}{|c|c|c|c|c|c|}
\hline \multicolumn{6}{|c|}{ Energy cost savings from district heat } \\
\hline Discount rate & $1 \%$ & $2 \%$ & $3 \%$ & $4 \%$ & $5 \%$ \\
\hline Saving $(€)$ & 23662 & 21094 & 18925 & 17084 & 15513 \\
\hline \multicolumn{6}{|c|}{$\begin{array}{l}\text { The energy cost difference between electric and district heating for an average house: } 170 \mathrm{~m}^{2} \text { (size), } 130 \mathrm{kWh} / \mathrm{m}^{2} \\
\text { (energy need). The number is the present-value of the } 25 \text {-year saving in } 2013 \text { when the annual saving is given by the } \\
\text { historical average energy cost difference obtained from electricity and district heat contract prices } 2006-2013 \text { in the } \\
\text { Helsinki metropolitan area. Electricity prices are from default contracts available to any household in the region (data } \\
\text { source: The Finnish Energy Industries and Energy Authority). }\end{array}$} \\
\hline
\end{tabular}

\section{Table 1:}

is a regulated default contract designed for customers without a market-based contract. Typically, it is offered by a municipal electricity utility having a pre-regulation history in the location of the customer. As of January 1, 2006, 100\% of consumers had the default contract and, thereafter, the fraction of default customers has gradually declined over time. The market shares of retailers and their contract types are not public information but according the industry specialists, the default contract type is still the dominant contract. Any customer can, at any time when not committed to a previous contract, take the default contract that may not be the cheapest available contract but it is typically favorably priced.

We used the default contract prices as the basis for the cost-estimate discussed above. To evaluate whether the default contract is representative, we collected data for all contracts offered in the Helsinki region during the deregulated era, from a database maintained by the Energy Authority in Finland $\sqrt[9]{ }$

Municipal district heating companies are natural monopolies, and therefore their pricing of heat is regulated. The price of heat is uniform for all customers in the municipality, and it follows a formula depending on fuel costs and electricity wholesale prices. Since the cost of heat is a function of the same input prices that underlie the electricity spot prices (and thus retail prices), it is not surprising that the pricing of district heat and electricity contracts are tightly connected. Moreover, the municipal pricing formulas are

\footnotetext{
${ }^{9}$ Energy Authority provides a public service for comparing currently offered contracts at http://www . energiavirasto.fi/en/home. However, the historical contracts are not publicly available but such a database has been compiled by Sahari (2013).
} 
not directly regulated but the overall mark-ups of the district heating companies are under the surveillance of the Competition Authority in Finland 10

Coming up with an informed evaluation of the energy cost difference between electric and district heating took a number of steps for us. Although the sources of data are publicly available, we could not find a ready-made comparison of the costs in the public domain. The view that we use to interpret the regression results, is that the housing market aggregates information on energy costs; the cost difference of using the technologies in houses may not be well understood by the general public.

\subsection{Houses}

We have three sources of register data: (i) detailed unit-level building characteristics, including the heating technologies in the Helsinki region (SeutuCD 2013); (ii) socioeconomic neighborhood characteristics on a 250mx250m grid (Statistics Finland 2013); and (iii) real unit-level transaction prices between 2001-2012 (NLS 2013). We restrict attention to single-owner detached houses so that the buyer of the house should in principle internalize the heating costs at purchase. We eliminate older houses that do not have reliable information on the heating technology; reliable information is available in Helsinki from 1981, in Vantaa from 1982 and in Espoo from 1984. This elimination also limits heterogeneity in the overall energy efficiency of houses; after the energy crises, the energy efficiency of new buildings became heavily regulated covering the thickness and materials of structures, windows, and even the use of space.11 Focusing on houses built under strict standards helps in controlling for the unobservable heterogeneities in our sample.

\footnotetext{
${ }^{10}$ There is a connection fee for joining the district heating network but this cost is sunk and not relevant for our study. The variable cost of use consist of the (i) energy charge and the (ii) power charge, tied to the contracted capacity or contracted water flow (HELEN contract information 2013). The amount of the energy charge depends on the fuels used and the variable costs in heat procurement. The power charge covers mainly the fixed costs of heat procurement. The market surveillance of district heating activities in Finland is based mainly on competition legislation and partly on the Electricity Market Act. Consumers also protected by the Consumer Protection Act. According to the Finnish Competition Authority, a district heat supplier holds a dominant market position. Twice a year (1 January and 1 July), the Finnish Energy Industries gathers information from district heating companies on the district heating prices for three new residential buildings of various sizes. Source: Finnish Energy Industries 2014.

${ }^{11}$ Based on personal communication with Pekka Kalliomaki, senior construction adviser at the Ministry of environment. See also Jokisalo (2008) for description of the building code and analysis.
} 


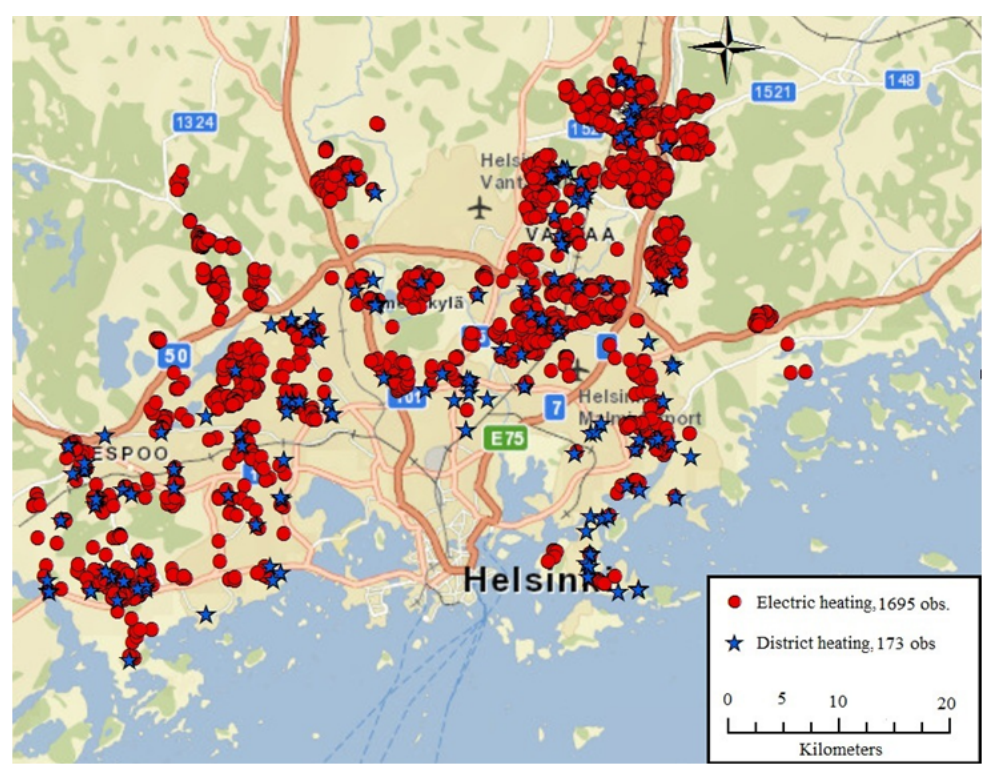

All single-family houses in the data with electric or district heating, traded in years 2001-2012.

Figure 2:

Overall, we have 1868 houses in our final dataset with the observable characteristics including the transaction price, one of the two heating technologies of interest, building material and other key house characteristics, location, and the socio-economic variables of the neighborhood. Fig. 2 puts the observations on the map; we have 1695 transactions of houses with electric heating and 173 transactions with district heating. The location of houses with district heating is obviously dictated by the district heat network, discussed in detail shortly, explaining the over-representation of electric heating when the distance from the city center sufficiently increases.

For the analysis, we define technology neighborhoods, that is, localities where both technologies are present, by spanning a 500mx500m grid on the map as the main case, and selecting only squares where technologies coexist. This procedure puts the focus on local markets and thereby controls maximally the local house price determinants; it gives minimal power to our test that the treatment effect from the technology is positive. We find it useful to start with all local covariates, and then increase to the size of the definition of the technology neighborhood to $1000 \mathrm{mx} 1000 \mathrm{~m}$, to $2000 \mathrm{mx} 2000 \mathrm{~m}$, and finally to the full sample to show that the treatment effect remains stable. In Fig. 3, we show the observations from the technology neighborhoods defined by the $500 \mathrm{mx} 500 \mathrm{~m}$ grid; there are 105 and 253 observations for district and electric heating, respectively, from such localities 12

\footnotetext{
${ }^{12}$ The respective numbers of observations increase to 141 and 592 for $1000 \mathrm{mx} 1000 \mathrm{~m}$, and to 166 and
} 


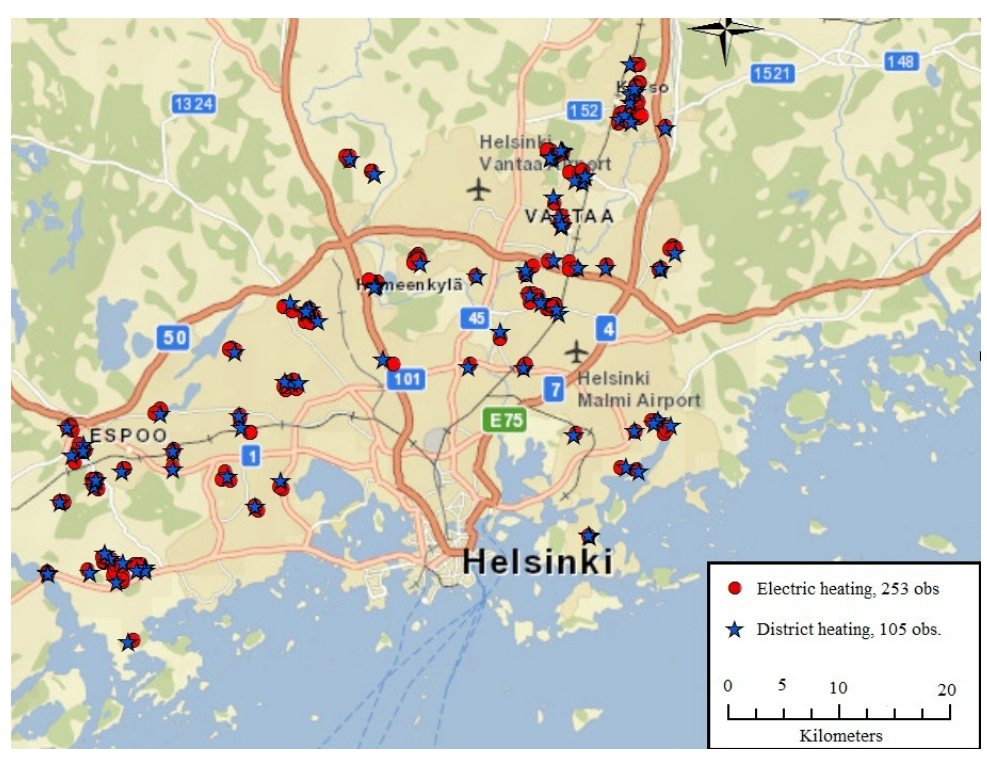

Technology neighborhoods $(500 \mathrm{~m} \times 500 \mathrm{~m})$ : localities where houses with both technologies were traded between 2001-2012.

Figure 3:

We look next at the descriptive details of houses and neighborhoods to see if there is any immediate evidence for selection into the technology groups. We discuss the observables for the $500 \mathrm{mx} 500 \mathrm{~m}$ neighborhoods to allow for variation in the socioeconomic variables that are measured at the $250 \mathrm{mx} 250 \mathrm{~m}$ grid (by the Statistics Finland)

Looking first at the observable socioeconomic characteristics of the technology neighborhoods in Table 2, we see no evidence of selection, based on observables, to technologies in the neighborhood characteristics for the two technologies; none of the observable socioeconomic variables are statistically different for the two technologies. If anything, one might expect that the more expensive (according to our hypothesis and the house descriptives presented shortly) district heating units would house higher-income and -educated individuals; however, the technology groups are practically identical in this respect. The same conclusion applies for the definitions of neighborhoods that cover larger areas 13

As to the house characteristics in the technology neighborhoods, reported in Table 9 . there is support for the conclusion that the houses connected to the district heat network are bigger and more expensive. The price correlation is not a main concern for selection; we expect such houses to be more expensive according to our main hypothesis. However, the size is a potential selection issue, although the mean difference is only about $10 \%$ of the average house size. There are also some differences in the building materials, which 991 for $2000 \mathrm{mx} 2000 \mathrm{~m}$ neighborhoods.

${ }^{13}$ The tables for the observable characteristics of the $1000 \mathrm{mx} 1000 \mathrm{~m}$ neighborhoods are in the Appendix. 


\begin{tabular}{|c|c|c|c|c|c|}
\hline & \multirow{2}{*}{\multicolumn{2}{|c|}{$\begin{array}{c}\text { District heating } \\
\mathrm{N}=105\end{array}$}} & \multirow{2}{*}{\multicolumn{2}{|c|}{$\begin{array}{c}\text { Electric heating } \\
\mathbf{N}=253\end{array}$}} & \multirow[b]{3}{*}{ diff. $^{A}$} \\
\hline & & & & & \\
\hline & mean & std.dev & mean & std.dev & \\
\hline Ownrate & 0.78 & 0.21 & 0.82 & 0.18 & -0.04 \\
\hline Mean income $(€)$ & 33421 & 7352 & 34248 & 6533 & -827 \\
\hline College degree & 0.29 & 0.13 & 0.31 & 0.12 & -0.02 \\
\hline Unemployment & 0.04 & 0.03 & 0.03 & 0.03 & 0.01 \\
\hline Service jobs/capita & 0.10 & 0.23 & 0.08 & 0.14 & 0.02 \\
\hline Nr. of buildings & 35 & 13 & 37 & 12 & -2.2 \\
\hline Mean area $\left(\mathrm{m}^{2}\right)$ & 105 & 21 & 108 & 21 & -2.5 \\
\hline Population & 159 & 76 & 152 & 60 & 6.6 \\
\hline
\end{tabular}

Table 2:

\begin{tabular}{|c|c|c|c|c|c|}
\hline & \multirow{2}{*}{\multicolumn{2}{|c|}{$\begin{array}{c}\text { District heating } \\
\mathrm{N}=105\end{array}$}} & \multicolumn{2}{|c|}{ Electric heating } & \multirow[b]{3}{*}{ diff. $^{A}$} \\
\hline & & & & & \\
\hline & mean & std.dev & mean & std.dev & \\
\hline Price per $\mathrm{m}^{2 \mathrm{~B}}$ & $2,2,881$ & $\bar{~} 1,120$ & 2,633 & 680 & $248^{*}$ \\
\hline Area $\left(\mathrm{m}^{2}\right)$ & 181 & 52 & 158 & 33 & $23^{*}$ \\
\hline Ventilation system & 0.69 & 0.47 & 0.73 & 0.45 & -0.04 \\
\hline \multicolumn{6}{|l|}{ Facade material } \\
\hline -brick & 0.46 & 0.50 & 0.46 & 0.50 & 0.00 \\
\hline -other ${ }^{\mathrm{C}}$ & 0.25 & 0.00 & 0.08 & 0.28 & $0.16^{*}$ \\
\hline -wood & 0.30 & 0.43 & 0.46 & 0.50 & $-0.16^{*}$ \\
\hline Age & 11.6 & 8.6 & 11.3 & 7.6 & 0.3 \\
\hline Multifloor & 0.64 & 0.48 & 0.5 & 0.5 & $0.16^{*}$ \\
\hline Lotsize & 877 & 306 & 815 & 272 & 62 \\
\hline Rooms & 4.9 & 0.9 & 4.7 & 0.9 & 0.2 \\
\hline CBD dist. $(m)^{\mathbf{D}}$ & 14,616 & 3,866 & 14,582 & 3,579 & 34 \\
\hline
\end{tabular}

Table 3: 


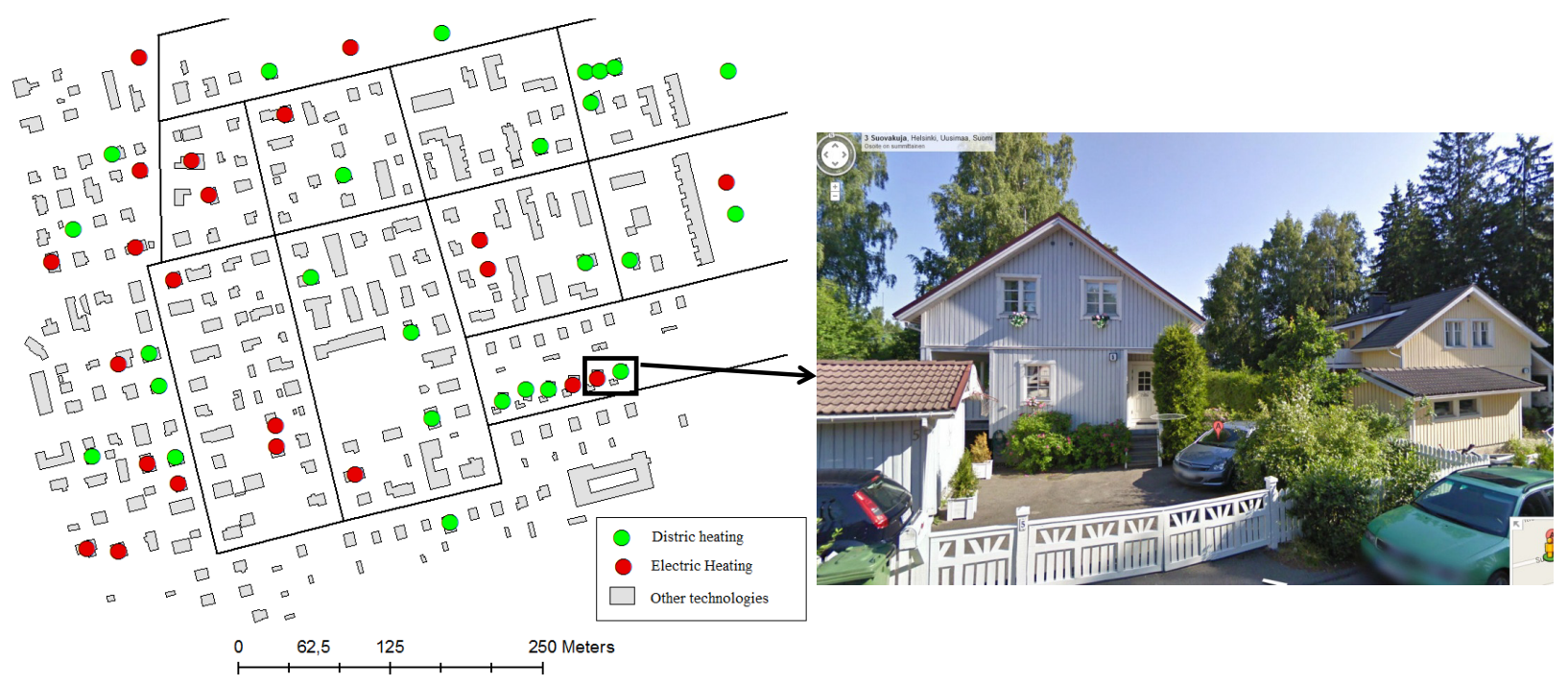

Illustration of houses with similar observable characteristics, excluding the heating technology. District heating was available for both houses at the time of construction.

Figure 4:

may be explained by the difference in the average size ${ }^{14}$

Based on the observables, should we expect that the district heating houses are better in some unobservable way? We will explicitly analyze the robustness of findings with respect to unobservables in later section. Here, to introduce our identification strategy, we shed light on the historical context that created the co-existence of different house types in the same neighborhood. How come otherwise similar houses differ in the technology dimension?

Houses are typically built for both technologies even when the district heating is available in the neighborhood. Fig 4 depicts such a neighborhood with houses built after 1981 (these houses are in our data-set). In fact, the two neighbors pictured are practically identical in terms of size, construction year and other observables - yet,

\footnotetext{
${ }^{14}$ To put these differences in the house characteristics into perspective, consider the following problem in the green label literature focusing on commercial sector buildings: "Nonrandom selection into the pool of certified buildings is evidenced by the observable characteristics of green buildings in comparison to the average office building: the typical green building is 15 stories high and measures over 300,000 square feet, in contrast with the average office building, which is about two stories high and measures about 20,000 square feet" (Papineua, 2013).
} 


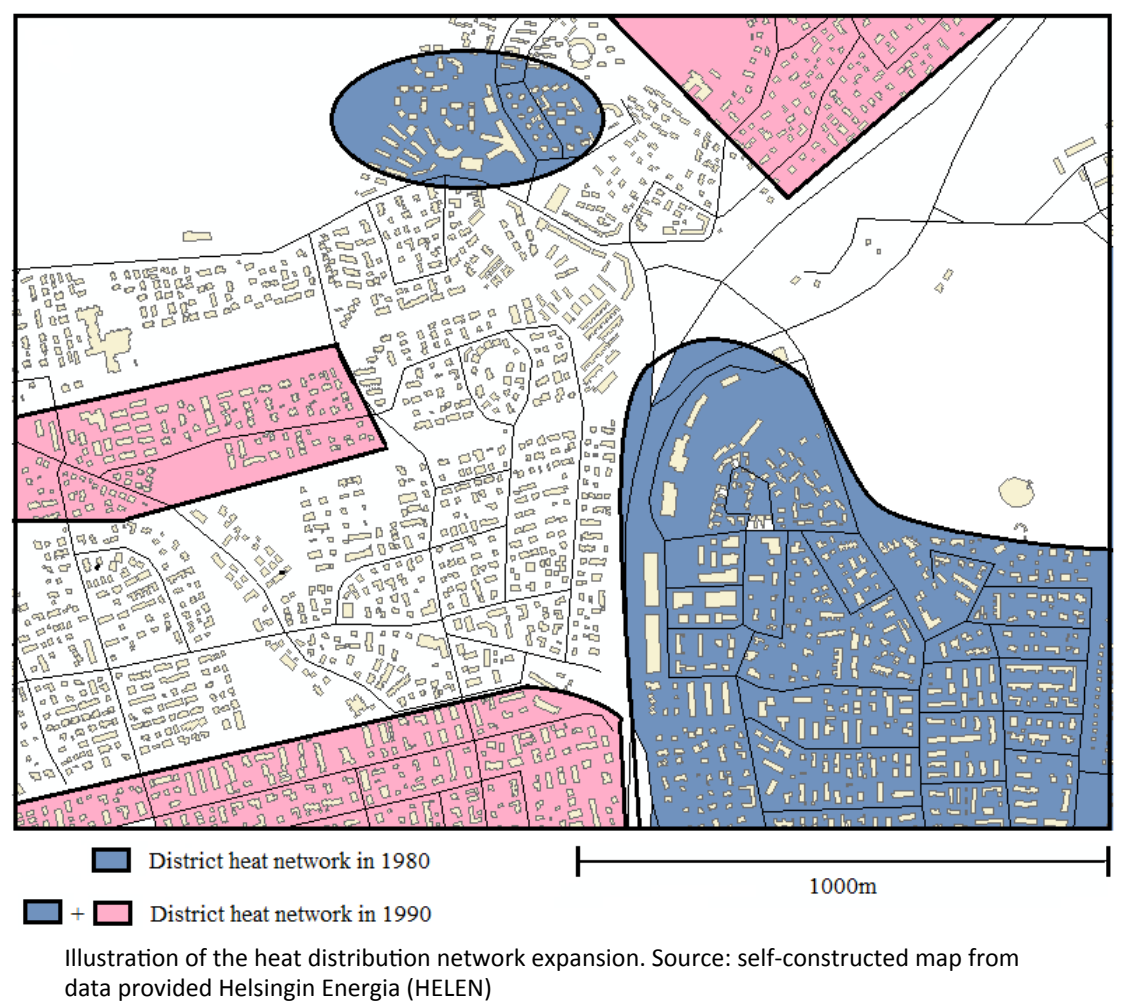

Figure 5:

only one of the houses is connected to the district heat network. Although currently there is a clear difference between the cost of using the technologies, the same did not apply for the total lifetime costs at the time of construction. It is not unreasonable to argue that the representative homebuilder was indifferent between the two technologies at the time of construction, without introducing deviations from efficient markets. At the time of construction, a homeowner investing in district heating pays a higher initial investment cost but expects to be compensated through the better financial performance of the heating system over time. If historical mortgage rates and terms can be used as a guide for understanding how patiently home builders are willing to wait for the returns from energy cost savings, then substantially higher rates and shorter horizons should be used for decisions made in the 1980s and early 1990s.

The financial sector was deregulated in late 1980s and in 1991-1993 Finland experienced the deepest recession observed in an industrialized country since the 1930s (see, e.g., Gorodnichenko et al., 2012), which kept the rates very high until late 1990s (see Appendix, Fig. 9, for the historical interest rates). Prior to this period, there was con- 


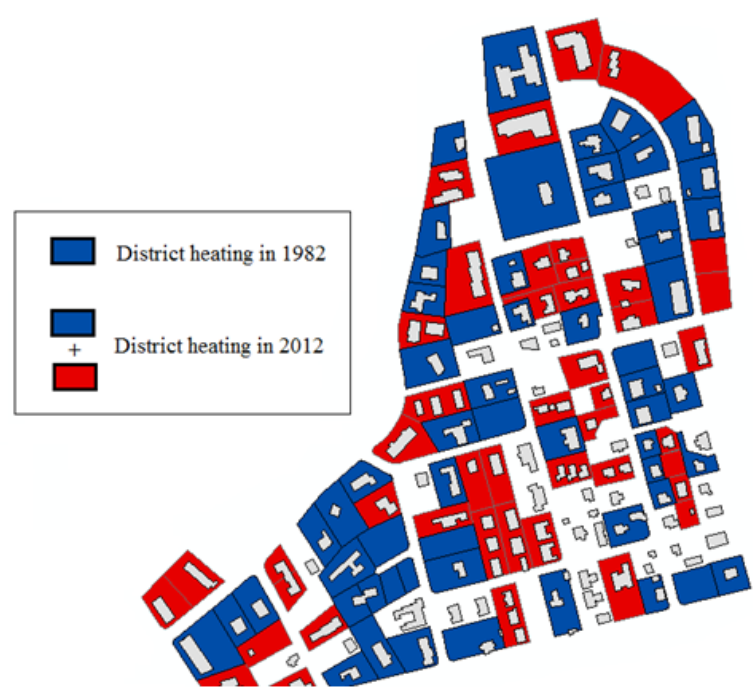

Old houses switching technologies: houses connected to the district heating network in 1983 and 2012 in a locality.

Figure 6:

tinual shortage of capital in the private sector; not only rates were high but also payback periods were typically in the range $10-15$ years ${ }^{15}$

Majority of the houses in our data were built in the 1980s and 1990s; the construction time nominal rates exceeded $10 \%$ as a rule, although the real rate was considerably lower. In Appendix (see Fig. 7), we build on a survey data on initial costs for the heating systems to illustrate the effect of real discounting on the total cost comparison between the systems; in addition, sufficiently restricting the payback period leads to the financial dominance of the electric heating, independently of discounting.

For further support, we look at surveys sent in total to ca. 15000 homebuilders by the Building Information Foundation RTS in years 2000-2011: $40 \%$ of all respondents chose the low investment cost as one of the main reasons for the technology choice in 2000; this number steadily declined to $20 \%$ by 2011 . This trend is consistent with longer planning horizons for decisions made in homebuilding. The survey results in general confirm that consumers view the technologies equally easy to use, and that there is no general intrinsic preference in either direction. 16

\footnotetext{
${ }^{15}$ See Tarkka (2009) for an overview of the Finnish financial deregulation in general.

${ }^{16} \mathrm{We}$ report the general trends in preferences as well as all the more detailed survey results for electric and heating technologies in the Appendix (see Figure 10 and Table 10). We thank RTS for providing
} 
However, not all houses were built for compatibility with district heating — water circulation could have been left out from the house structures because of the distance to the network at the time of construction. The map in Fig. 5 shows the boundary of the network in 1980, and also in 1990 in a locality. Clearly, at the time of construction, the connection to the network was not an option for all units, although later on the network expanded to close vicinity of most electrically heated houses. 17

The final channel for selection into the district heating group consists of houses joining the heat distribution network from other technologies, provided the network becomes available and the house has the water circulation in the structures. Fig. 6]illustrates the first case by showing a neighborhood where the network is available in 1983 but only a fraction of the houses is connected. In year 2012 majority of the houses are connected. In our empirical analysis, we exclude such old switching houses since the data about the state of the technology is not reliable and since the fleet of old houses is heterogeneous with respect to energy efficiency in general.

To sum up, we see no compelling reason to think that houses with electric heating have worse unobservable characteristics than those originally built for other technologies. In contrast, in the 1980, electricity was seen to be the technology of the future and rapidly expanding in Finland (see Kasanen and Lakshamanan 1989). Still in 2001-2012, close to $50 \%$ of all new houses in Finland chose electric heating, although combined with more sophisticated other technologies than in the decades before (Sahari, 2013).

\section{Regression results}

Our identification strategy is based on the variation of the observable house characteristics. The final service from the energy use (heat) is assumed to be experienced similarly irrespective of the source of energy; we see no compelling reason for this assumption not to hold. Based on the historical context that created the variation in the technology choices and also the tight energy efficiency regulations for buildings, we assume that houses with one technology instead of another have no better or worse overall unobserv-

the data and Anna Sahari for restructuring it.

${ }^{17}$ Some areas were excluded as part of the heat network expansion plan. To help households in planning, municipal policy-makers made long-term and publicly communicated plans for the network service (personal communication, Helsingin Energia (HELEN) 2014). Plans have subsequently changed: the network service is no longer a municipal utility but a power and heat business competing for customers by expanding the network to previously blank regions. Thus, unanticipated policy changes can also explain why the technologies co-exist. 
able characteristics. Finally, since there is a clear and stable difference in the energy costs, as well as an irreversible lock-in to the technologies, the house transaction price should capture the capitalized cost difference between the technologies.

\subsection{Main results}

We are interested in the contribution of the heating technology to single-family house prices. To this end, we regress the log of the price on the hedonic house characteristics by estimating:

$$
\ln p_{i, l, t}=\beta h_{i}+\gamma X_{i}+\phi N_{l}+u_{i, l}+y_{i, t}+\epsilon_{i, l, t}
$$

Here, $\ln p_{i, l, t}$ is the $\log$ of the house $i$ sales price in location $l$ in year $t$. Technology $h_{i} \in$ $\{E, D H\}$ is either electricity (E) or district heat (DH). The set of house and neighborhood characteristics are as described above, and $\epsilon_{i, l, t}$ is the error term. We introduce a set of dummy variables, $u_{i, l}$, for each technology neighborhood. Note that the socio-economic neighborhood characteristics are defined on a $250 \mathrm{mx} 250 \mathrm{~m}$ grid, and the fixed effects for each technology neighborhood are introduced to allow for unobservable neighborhood characteristics. The standard errors are clustered at the level of the zip codes 18 To control for the transaction date, we introduce transaction-year dummies.

In Table 4, which shows our main results, house characteristics are added column by column. Working backwards from the last column, after the full set of covariates, the heating technology has close to $6 \%$ impact on the house value - for an average house, this premium is strikingly close to the capitalized cost saving, as discussed shortly. Previous column, the fourth, drops the distance to the city center, which leaves the estimate intact. Columns 3 and 2 leave out house characteristics such as the number of floors and rooms (column 3), and age of the house (column 2), leading to an increase in the estimate first to $7.5 \%$ and then to $8.5 \%$. Finally, when the size of the house left out as a control, the estimate jumps to $17 \%$.

The coefficient of the technology stabilizes before the full set of observables is exhausted. Although this heuristics as such is frequently used as suggestive evidence for the treatment effect not be biased due to omitted unobservable variables, we will explicitly analyze the size of the potential bias in Section 3.3, following Oster (2014). Since our R-squared is high and because its movement is strongly related to the addition of

\footnotetext{
${ }^{18}$ The results are robust to clustering of errors at the neighborhood level; we believe clustering by zip code is the most conservative choice.
} 


\begin{tabular}{|c|c|c|c|c|c|}
\hline & (1) & (2) & (3) & (4) & (5) \\
\hline \multirow[t]{2}{*}{ District heating } & $0.169 * * *$ & $0.083 * *$ & $0.074 * *$ & $0.057 * *$ & $0.057 * * *$ \\
\hline & {$[0.043]$} & {$[0.035]$} & {$[0.030]$} & {$[0.023]$} & {$[0.021]$} \\
\hline \multirow[t]{2}{*}{$\log \left(\right.$ Area $\left.m^{2}\right)$} & & $0.698 * * *$ & $0.620 * * *$ & $0.600 * * *$ & $0.513 * * *$ \\
\hline & & {$[0.082]$} & {$[0.078]$} & {$[0.067]$} & {$[0.078]$} \\
\hline \multirow[t]{2}{*}{ Ventilation system (1=yes) } & & & $0.116^{* * * *}$ & $0.058 * *$ & $0.067 * *$ \\
\hline & & & {$[0.023]$} & {$[0.028]$} & {$[0.027]$} \\
\hline \multicolumn{6}{|c|}{ Facade material (wood omitted) } \\
\hline \multirow[t]{2}{*}{-brick } & & & -0.028 & 0.022 & 0.027 \\
\hline & & & {$[0.026]$} & {$[0.023]$} & {$[0.023]$} \\
\hline \multirow[t]{2}{*}{-other ${ }^{A}$} & & & $0.145^{* * *}$ & $0.152 * * *$ & $0.155 * * *$ \\
\hline & & & {$[0.052]$} & {$[0.038]$} & {$[0.035]$} \\
\hline \multirow[t]{2}{*}{$\log ($ Age $)$} & & & & $-0.113 * * *$ & $-0.118 * * *$ \\
\hline & & & & {$[0.018]$} & {$[0.019]$} \\
\hline \multirow[t]{2}{*}{ Multifloor } & & & & & $0.033^{*}$ \\
\hline & & & & & {$[0.019]$} \\
\hline \multirow[t]{2}{*}{$\log \left(\right.$ Lotsize $\left.\mathrm{m}^{2}\right)$} & & & & & $0.165^{* *}$ \\
\hline & & & & & {$[0.065]$} \\
\hline \multirow[t]{2}{*}{ Number of rooms } & & & & & -0.019 \\
\hline & & & & & {$[0.012]$} \\
\hline \multirow[t]{2}{*}{ CBD distance $^{\mathrm{B}}$} & & & & & 0 \\
\hline & & & & & {$[0.000]$} \\
\hline \multirow[t]{2}{*}{ Constant } & $12.093 * * *$ & $8.210 * * *$ & $8.270 * * *$ & $8.329 * * *$ & $7.601 * * *$ \\
\hline & [1.661] & [1.178] & [0.999] & {$[0.872]$} & [1.539] \\
\hline Observations & 358 & 358 & 358 & 358 & 358 \\
\hline R-squared & 0.69 & 0.8 & 0.83 & 0.87 & 0.88 \\
\hline Neighborhood char. $^{\mathrm{C}}$ & yes & yes & yes & yes & yes \\
\hline Near n'hood fixed effects & yes & yes & yes & yes & yes \\
\hline Year fixed effects & yes & yes & yes & yes & yes \\
\hline
\end{tabular}

Table 4: 


\begin{tabular}{l}
\hline Energy cost capitalization for an average house \\
\hline \hline
\end{tabular}

Table 5:

observable house price determinants, the room for the bias is small, as will be seen. Moreover, despite the very small sample size for this 500mx500m technology neighborhood, 105 district and 253 electric heating houses, there is enough power to identify the effect. As we increase the size of the sample by scaling up the technology neighborhoods until reaching the full sample in the next Section, the treatment effect will remain stable.

Looking at the main effect expressed in euros, in Table 5, we come to a number that is very close to the capitalized cost savings presented in earlier Table 1. The calculation of the implied discount rate uses the monetized main effect from the regression analysis and builds on the same assumptions that were used for calculations in Table $1 \|^{19}$ The resulting low discount rate of $2 \%$ for cost savings is not far from the real mortgage rates during the period of transactions in our data (2001-2012). While the standard errors in euros are still large, it is notable that even the upper $95 \%$ confidence limit remains below $7 \%$ discounting - a number that is quite reasonable in contrast with 25-30\% range of the seminal papers in the literature on Energy Paradox by Hausman (1979) and Dubin and McFadden (1984).

\subsection{Robustness: technology neighborhoods}

To control for the unobservable neighborhood characteristics and also for the fact that the heat distribution network is not available in all locations, we selected the sample in the above analysis based on those 500x500m squares where houses with both technologies were transacted. This minimizes the potential bias in the estimate of the main effect but leads to a rather small sample size. Consider now expanding the grid size too see

\footnotetext{
${ }^{19}$ See the text under the Table.
} 


\begin{tabular}{|c|c|c|c|c|}
\hline & (1) & (2) & (3) & (4) \\
\hline Distric heating & $\begin{array}{c}0.057 * * * \\
{[0.021]}\end{array}$ & $\begin{array}{c}0.065 * * * \\
{[0.022]}\end{array}$ & $\begin{array}{l}0.048 * * \\
{[0.022]}\end{array}$ & $\begin{array}{c}0.061 * * * \\
{[0.022]}\end{array}$ \\
\hline R-squared & 0.88 & 0.79 & 0.73 & 0.65 \\
\hline $\mathrm{N}$ & 358 & 733 & 1157 & 1868 \\
\hline Fixed effects & $500 \mathrm{~m} \times 500 \mathrm{~m}$ & $1000 \mathrm{~m} \times 1000 \mathrm{~m}$ & $2000 \mathrm{~m} \times 2000 \mathrm{~m}$ & $\begin{array}{l}\text { No FE, full } \\
\text { sample OLS }\end{array}$ \\
\hline $\begin{array}{l}\text { Unit characteristics }{ }^{A} \\
\text { Neighborhood characteristics }{ }^{B} \\
\text { Year fixed effects }\end{array}$ & $\begin{array}{l}\text { yes } \\
\text { yes } \\
\text { yes }\end{array}$ & $\begin{array}{l}\text { yes } \\
\text { yes } \\
\text { yes }\end{array}$ & $\begin{array}{l}\text { yes } \\
\text { yes } \\
\text { yes }\end{array}$ & $\begin{array}{l}\text { yes } \\
\text { yes } \\
\text { yes }\end{array}$ \\
\hline $\begin{array}{l}\text { The effect of the technology on the house } \\
1 \% \text { level, }{ }^{* *} 5 \% \text { level, }{ }^{*} 10 \% \text { level. Standa } \\
\text { age, multifloor, lotsize, number of rooms a } \\
\text { housing, mean income, share that have coll } \\
\text { population. }\end{array}$ & $\begin{array}{l}\text { varied sizes of the te } \\
\text { are clustered within } \\
\text { distance. B Neighbo } \\
\text { ee, unemployment } \mathrm{r}\end{array}$ & $\begin{array}{l}\text { ogy neighborhood. Notes } \\
\text { ode area. }{ }^{\wedge} \text { Unit characte } \\
\text { characteristics }(250 \mathrm{~m} \mathrm{x} \\
\text { rvice jobs per capita, nu }\end{array}$ & $\begin{array}{l}\text { stimated coefficient is st } \\
\text { tics include area, air con } \\
\text { Om squares) include: shar } \\
\text { er of buildings, mean are }\end{array}$ & $\begin{array}{l}\text { ally significant at }{ }^{*} \\
\text { ing, facade materia } \\
\text { wner occupied } \\
\text { uildings and }\end{array}$ \\
\hline
\end{tabular}

Table 6:

how sensitive the results are to the chosen size of the technology neighborhood. In Table 6, we report four experiments including the above reported main case together with 1000x1000m and 2000x2000m grids for selecting the houses, and finally full sample without restrictions on the house selection. The general conclusion is clear: the size of the main affect does not critically depend on how the houses are chosen to the sample. The last column with full sample leads to an almost identical estimate; controlling for the distance to the city center is enough for capturing the relevant locality information.

\subsection{Robustness: selection bias}

We cannot rule out a scenario that houses with district heating have, for example, higher quality interior designs on average. Although selection mechanisms based on such unobservables are unlikely, the potential bias in the treatment effect should be systematically evaluated. We follow Altonji, Elder and Taber (2005) and also Oster (2014) to quantitatively assess the potential bias due to unobservable factors. The robustness analysis here invokes the proportional selection assumption - the observed controls contribute to the treatment effect in a way that is informative about the relationship between the unobserved elements and the treatment effect (see Altonji et al. for the formal definition). This relationship is described by a constant degree of proportionality, denoted by $\delta$. When the unobserved controls have no contribution to the main effect of interest, $\delta=0$; if they are 
equally important as the observed controls, $\delta=1$. For intuition, suppose hypothetically that the full set of conceivable controls is available but, for the sake of illustration, the control set is randomly chosen. In this case, $\delta=1$ would explicitly apply. However, since the choice of controls is typically better than random, the unobserved elements of the model have a contribution that justifies a value for $\delta$ that is on average less than unity, so that $\delta \in[0,1]$ is the reasonable bounding set for the degree of selection. The value for $\delta$ cannot be estimated, but we can experiment how different degrees of omitted variables contribution translate into a bias in the estimated main effect. In particular, we can find the value for $\delta$ that leads to a zero for the treatment effect.

Once $\delta$ is assumed it is possible to estimate the unbiased treatment effect; that is, the effect of district heating on the house price in our case. Table 7 (left) reports this robustness analysis for $\delta \in[0,1]$. In the estimation, we include a full set of controls that leads to the main effect of $5.7 \%$ in Table 4 (last column); for this regression, we then add unobservable elements as captured by $\delta$. "Beta" for district heating is equal to our estimated main effect when $\delta=0$; the coefficient gradually declines, as expected, when the importance of unobservables is increased. If we accept $\delta \in[0,1]$ as a reasonable bound, it follows that even in the most conservative case $(\delta=1)$ the impact on the house value is still $4 \%$; this implies a premium of about 15000 euros for district heating houses and thus an implied discount rate of $5 \%$, based on the cost savings obtained from our contract data and a 25-years horizon. The last line of the Table reports the value $\delta=2.6$ for which the treatment effect is zero. Notably, one would need to assume that our selection of controls is much worse than a random selection of controls to eliminate the main effect fully.

The robustness analysis with respect to $\delta$ in Table 7 (left) is conservative for a reason that we have not yet discussed - it assumes that the theoretical maximum for R-squared, denoted by $R_{\max }$, is unity. In reality, there is also pure noise in the model even after the inclusion of the full set of controls, thereby leading to a lower theoretical maximum for R-squared and also to a lower potential contribution from the unobservables. Table 7 (right) reports $R_{\max }$ that is consistent with unbiased "beta" under the conservative assumption that the controls are randomly selected; the observable and unobservable elements of the model are thus equally important $(\delta=1)$. When $R_{\max }=.88$, R-squared from our main estimation equal to the theoretical maximum, and therefore there is no bias in the estimated beta. When the theoretical maximum departs above the actual, the bias in the estimate increases. However, the unbiased estimate cannot go below the $4 \%$ as the R-squared must remain below unity. 


\begin{tabular}{cc}
\hline coefficient & $\delta$ \\
\hline \hline 0.057 & 0 \\
0.054 & 0.2 \\
0.05 & 0.4 \\
0.046 & 0.6 \\
0.042 & 0.8 \\
0.04 & 1 \\
0 & 2.6 \\
\hline
\end{tabular}

The unbiased point estimate of the effect technology on the house price for a given degree of proportional selection measured by $\delta$ ( $\delta=0$ for no unobservable omitted variables; $\delta=1$ for random selection of covariates) when $\mathrm{R}^{\max }=1$.

\begin{tabular}{cc}
\hline coefficient & $\mathrm{R}_{\max }$ \\
\hline \hline 0.057 & N.A. \\
0.055 & 0.89 \\
0.052 & 0.91 \\
0.049 & 0.93 \\
0.046 & 0.95 \\
0.042 & 0.97 \\
0.04 & 1 \\
\hline
\end{tabular}

The unbiased point estimate of the effect technology on the house price when the theoretical $\mathrm{R}$ squared $\left(R^{\max }\right)$ is varied between .88 (from the estimation) and unity, and when $\delta=1$.

Table 7:

\section{Concluding Remarks}

"We must look at the price system as such a mechanism for communicating information if we want to understand its real function [...] The most significant fact about this system is the economy of knowledge with which it operates, or how little the individual participants need to know in order to be able to take the right action. "-Hayek (1945).

This paper has produced the result that the Finnish housing market aggregates information about cost savings provided by energy technologies. The result is a contribution to the literature on the "Energy Paradox" because it clarifies the conditions under which the market has no difficulties in rewarding energy-efficient technologies. In our empirical setting, the cost savings are relatively predictable, technologies do not seriously confound with other attributes of the good, heterogeneities of the objects traded are appropriately controlled, and the technologies have significant budgetary effects for consumers.

The result provides indirect support for the energy-efficiency certification systems in the housing market that have been introduced both in the EU and US: having transparent information about the technological properties of the house can significantly affect the house value. By design, the information is transparent in our setting as the fleet of houses 
relatively uniform and the technology is easily observable. This is not necessarily the case when houses differ multiple energy-efficiency related dimensions, making the certification schemes valuable.

\section{References}

[1] Allcott, Hunt, and Nathan Wozny (2012). Gasoline Prices, Fuel Economy, and the Energy Paradox. Forthcoming, Review of Economics and Statistics.

[2] Allcott, Hunt, and Michael Greenstone (2012).Is There an Energy Efficiency Gap? Journal of Economic Perspectives, Vol. 26, No. 1 (Winter), pages 3-28.

[3] Allcott, Hunt, and Sendhil Mullainathan (2010). Behavior and Energy Policy. Science, Vol. 327, No. 5970 (March 5), pages 1204-1205.

[4] Altonji, J., T. Elder, and C. Taber, 2005. Selection on Observed and Unobserved Variables: Assessing the Effectiveness of Catholic Schools, Journal of Political Economy, 113(1): 151-184.

[5] Bento,A.M., S. Li, K. Roth, Is there an energy paradox in fuel economy? A note on the role of consumer heterogeneity and sorting bias, Economics Letters, Volume 115, Issue 1, April 2012, Pages 44-48,

[6] Busse, Meghan R., Christopher R. Knittel, and Florian Zettelmeyer (2013). "Are Consumers Myopic? Evidence from New and Used Car Purchases." American Economic Review, 103(1): 220-56.

[7] Dubin, J.A., and McFadden, D. L (1984), An Econometric Analysis of Residential Electric Appliance Holdings and Consumption, Econometrica, Econometric Society, vol. 52(2), pages 345-62, March.

[8] Eichholtz, P., N. Kok, and J.M. Quigley (2013). The Economics of Green Building, Review of Economics and Statistics, 95:1, 50-63.

[9] Gorodnichenko, Yuriy, Enrique G. Mendoza, and Linda L. Tesar. 2012. "The Finnish Great Depression: From Russia with Love." American Economic Review, 102(4): 1619-44. 
[10] Hausman, J., (1979), Individual Discount Rates and the Purchase and Utilization of Energy-Using Durables, The Bell Journal of Economics, Vol. 10, No. 1 (Spring, 1979), pp. 33-54.

[11] Hayek, F., The use of knowledge in society (1945), The American Economic Review, 35, 519530.

[12] IPCC (2014), Working Group III contribution to the IPCC 5th Assessment Report "Climate Change 2014: Mitigation of Climate Change", Buildings.

[13] Jaffe, A.B., and R. N. Stavins (1994). The energy paradox and the diffusion of conservation technology, Resource and Energy Economics, Volume 16, Issue 2, May 1994, Pages 91-122.

[14] Jokisalo, J. (2008). On design principles and calculation methods related to energy performance of buildings in Finland. TKK Dissertations 144, Espoo 2008.

[15] Kahn, M.E., and N. Kok (2013). The capitalization of green labels in the California housing market, Regional Science and Urban Economics, Available online 13 July 2013.

[16] Kahn, M.E, N. Kok, J.M. Quigley (2014). Carbon emissions from the commercial building sector: The role of climate, quality, and incentives, Journal of Public Economics, Volume 113, May 2014, Pages 1-12,

[17] Kok, N., M. McGraw, and J. M. Quigley (2011). "The Diffusion of Energy Efficiency in Building." American Economic Review, 101(3): 77-82.

[18] Kasanen P., and T. R. Lakshmanan (1989). Residential Heating Choices of Finnish Households, Economic Geography, Vol. 65, No. 2 (Apr., 1989), pp. 130-145

[19] NLS 2013, National Land Survey of Finland.

[20] Oster, E. (2014), Unobservable Selection and Coefficient Stability: Theory and Validation, working paper.

[21] Papineau, M (2013), Energy Codes and the Landlord-Tenant Problem, working paper.

[22] Pippuri, P. (2012), Heating mode choices of Finnish households and the Energy Paradox, Masters thesis, Aalto University, department of economics. 
Tarkka, P. (2009), Financial Regulation in Finland from the 1950s Until the 1980s: Stability at What Price?, Bank of Finland, A paper prepared for the conference Financial market regulation after financial crises: the historical experience.

[23] Sallee, J.M, S.T. Anderson, and R. Kellogg (2013), What Do Consumers Believe About Future Gasoline Prices?, Journal of Environmental Economics and Management, vol. 66 n. 3, pp. 383-403.

[24] Sahari, A. (2013), Finnish households' choice of heating technology, thesis manuscript, Aalto University.

[25] SeutuCD - Greater Helsinki database (HSY) 2013. 
APPENDIX 


\begin{tabular}{|c|c|c|c|c|c|}
\hline & \multirow{2}{*}{\multicolumn{2}{|c|}{$\begin{array}{c}\text { District heating } \\
\mathrm{N}=141\end{array}$}} & \multicolumn{2}{|c|}{ Electric heating } & \multirow[b]{3}{*}{ diff. $^{A}$} \\
\hline & & & & & \\
\hline & mean & std.dev & mean & std.dev & \\
\hline Ownrate & 0.75 & 0.24 & 0.81 & 0.19 & -0.06 \\
\hline Mean income $(€)$ & 33278 & 7821 & 33376 & 6307 & -98 \\
\hline College degree & 0.29 & 0.14 & 0.29 & 0.12 & -0.004 \\
\hline Unemployment & 0.04 & 0.04 & 0.04 & 0.04 & 0.006 \\
\hline Service jobs/capita & 0.12 & 0.44 & 0.08 & 0.16 & 0.04 \\
\hline Nr. of buildings & 33 & 13 & 37 & 12 & -3.5 \\
\hline Mean area $\left(\mathrm{m}^{2}\right)$ & 102 & 21 & 108 & 21 & -5 \\
\hline Population & 160 & 78 & 148 & 71 & 11.1 \\
\hline
\end{tabular}

Observable socio-economic characteristics, $1000 \times 1000 \mathrm{~m}$ grid. Notes: ${ }^{\mathrm{A}}$ Differences that are statistically different at least at $5 \%$ level are marked with a star $\left(^{*}\right)$

Table 8:

\begin{tabular}{|c|c|c|c|c|c|}
\hline & \multicolumn{2}{|c|}{ District heating } & \multicolumn{2}{|c|}{ Electric heating } & \multirow[b]{3}{*}{ diff. $^{A}$} \\
\hline & \multicolumn{2}{|c|}{$\mathrm{N}=141$} & \multicolumn{2}{|c|}{$\mathrm{N}=592$} & \\
\hline & mean & std.dev & mean & std.dev & \\
\hline Price per $\mathrm{m}^{2 \mathrm{~B}}$ & 2,964 & 1,209 & 2,634 & 804 & $330^{*}$ \\
\hline Area $\left(\mathrm{m}^{2}\right)$ & 176 & 50 & 159 & 35 & $17^{*}$ \\
\hline Ventilation system & 0.70 & 0.46 & 0.70 & 0.46 & -0.04 \\
\hline \multicolumn{6}{|l|}{ Facade material } \\
\hline -brick & 0.44 & 0.50 & 0.50 & 0.50 & 0.06 \\
\hline -other ${ }^{\mathrm{C}}$ & 0.27 & 0.00 & 0.09 & 0.28 & $0.18^{*}$ \\
\hline -wood & 0.29 & 0.45 & 0.42 & 0.49 & $-0.13^{*}$ \\
\hline Age & 11.4 & 8.5 & 11.6 & 7.6 & 0.15 \\
\hline Multifloor & 0.59 & 0.49 & 0.5 & 0.5 & $0.1^{*}$ \\
\hline Lotsize & 867 & 306 & 855 & 401 & 12 \\
\hline Rooms & 4.8 & 0.9 & 4.6 & 0.9 & 0.19 \\
\hline CBD dist. ${ }^{\mathbf{D}}$ & 14,386 & 4,430 & 14,565 & 3,858 & 178 \\
\hline
\end{tabular}

Table 9: 


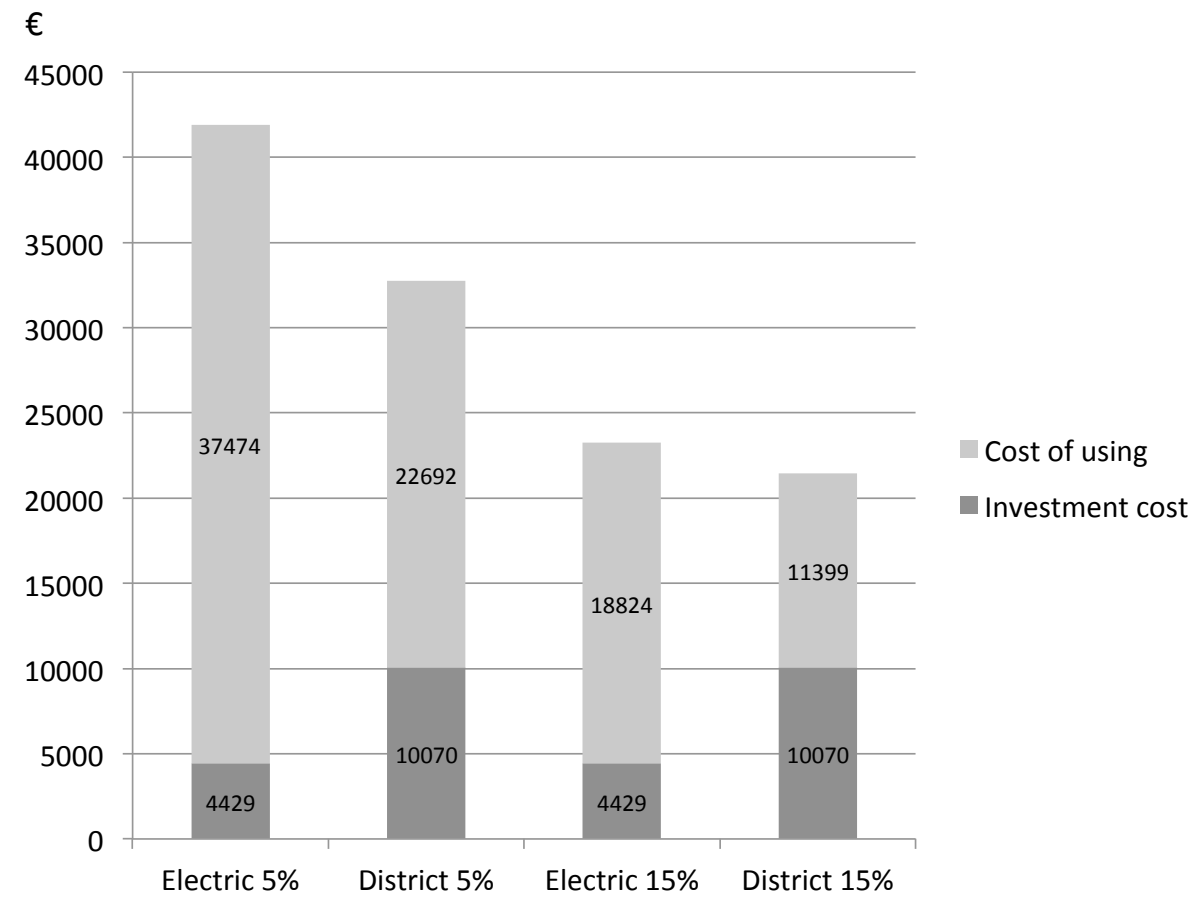

Illustration of the life-time cost of the heating systems for an average house in Finland in 2013 euros. Source for the investment costs: Building Information Foundation RTS, survey 2010. Cost of using the technologies is calculated from the contract prices in Table 1, using 25 years of lifetime and the reported discount rates.

Figure 7: 


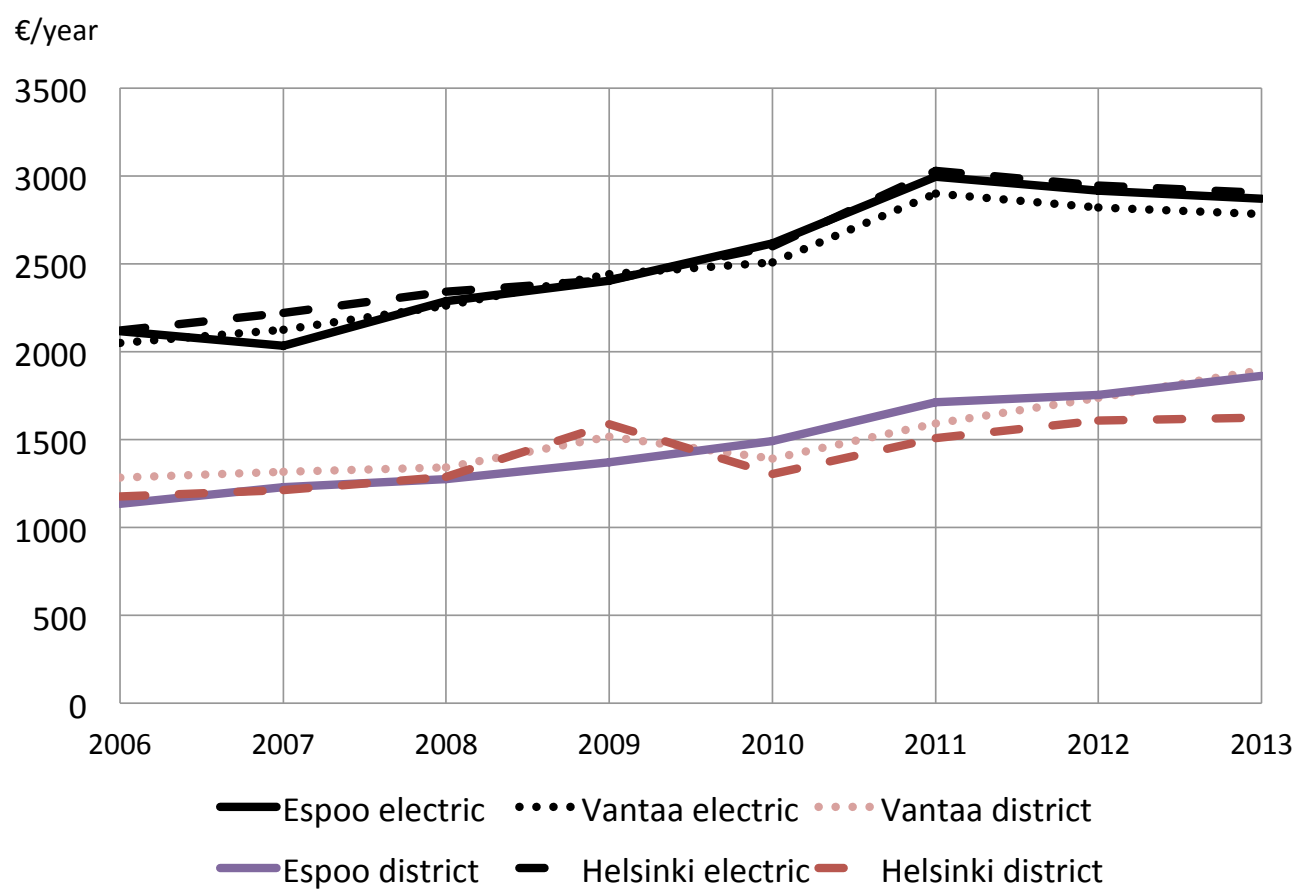

Annual cost in 2013 euros of the reported years, house size $170 \mathrm{~m}^{2}$ with energy need $130 \mathrm{kWh} / \mathrm{m}^{2}(22100 \mathrm{kWh}$ per year). Obtained from electricity and district heat contract prices 2006-2013 in the Helsinki metropolitan area. Electricity prices are from default contracts available to any household in the municipal area. Data source for electricity contracts: Energy Market Authority. District-heat contract prices follow a uniform pricing rule in the municipal areas; the calculation of costs for an average house is based on the formula. Data source for district-heat contracts: Finnish Energy Industries.

\section{Figure 8:}




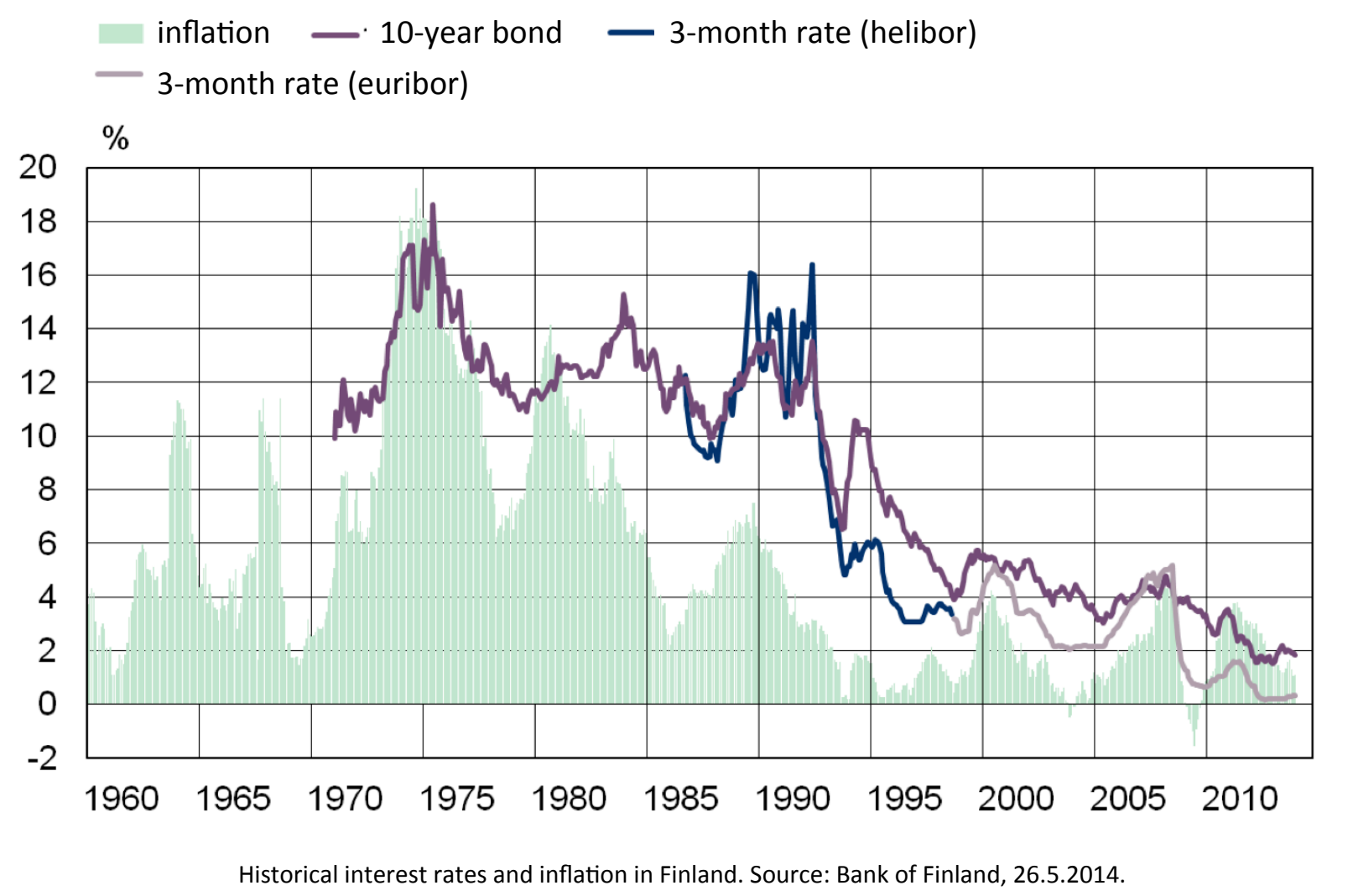

Figure 9: 


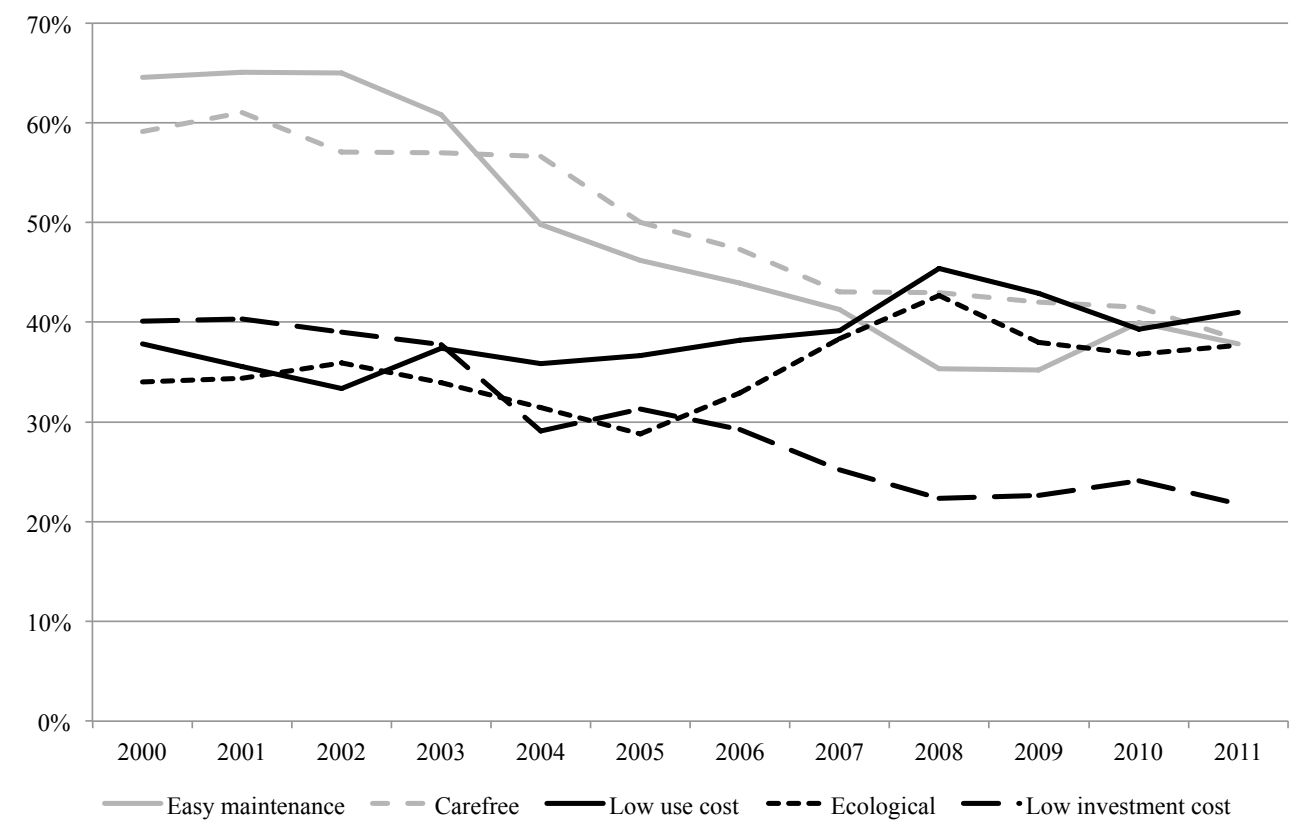

Trends in consumer preferences for heating technologies: Shares of homebuilders who reported a given attribute as one of the main reasons for choosing the technology. Source: annual survey waves 2000-2011 to homebuilders (the Building Information Foundation RTS).

Figure 10: 


\begin{tabular}{lccc}
\hline \multicolumn{1}{c}{ Variable } & Obs & $\begin{array}{c}\text { Direct } \\
\text { electric }\end{array}$ & $\begin{array}{c}\text { District } \\
\text { heat }\end{array}$ \\
\hline \hline No radiators & 14793 & 0.53 & 0.47 \\
Easy maintenance & 18895 & 0.69 & 0.55 \\
Carefree & 18895 & 0.68 & 0.66 \\
Low UC & 18895 & 0.11 & 0.49 \\
Ecological & 14793 & 0.17 & 0.21 \\
Low FC & 18895 & 0.60 & 0.14 \\
Reliability & 14793 & 0.42 & 0.15 \\
Healthy & 14793 & 0.22 & 0.19 \\
Own experience & 14793 & 0.42 & 0.15 \\
Own fuel & 18895 & 0.25 & 0.05 \\
Friend experience & 18895 & 0.19 & 0.15 \\
Safe for kids & 14793 & 0.21 & 0.12 \\
Can switch & 18895 & 0.02 & 0.09 \\
Expert recommend. & 18895 & 0.10 & 0.16 \\
Factory recommend. & 18895 & 0.07 & 0.03 \\
Required & 14793 & 0.01 & 0.44 \\
Other & 14793 & 0.03 & 0.03 \\
\hline
\end{tabular}

Reported consumer preferences for heating technologies: shares of homebuilders who reported a given attribute as one of the main reasons for choosing the technology. Summary over annual surveys 2000-2011 (Building Information Foundation RTS). Note: "required" refers to areas where district heating technology is a precondition for the license to build; this restriction does not apply to houses in our data. "No radiators" refers to technologies where the heat is delivered through the structures of the house such as floors. "Factory recommend." refers to house packages where the provided recommends a technology.

Table 10: 